\title{
Using audit to improve senior house officer training
}

\author{
Antony Johansen
}

\begin{abstract}
Summary
The British Geriatrics Society has described 16 training objectives for senior house officers (SHOs) in geriatric medicine. We have developed these into an audit standard, and in a controlled trial we consider the effectiveness of audit as a means of monitoring and improving SHO training.
\end{abstract}

SHOs from three hospitals were sent a questionnaire asking about the adequacy of formal and informal training for each objective; there was a response rate of $87 \%$. Results were presented at an audit meeting in one hospital, inadequacies of training identified and the hospital's programme of teaching modified appropriately. Two control hospitals remained unaware of the audit findings and were therefore unable to modify their training programmes. Re-audit at six months completed the audit cycle; the control hospitals showing no change between the two audits. In the intervention hospital the adequacy of training over the 16 objectives improved from $59 \%$ at first audit to $73 \%$ at re-audit. The initial audit had highlighted three target objectives as needing special attention; here the improvement from $38 \%$ to $69 \%$ was even more impressive, and statistically significant at $p<0.05$ on $\chi^{2}$ test.

Thus, although a questionnaire approach is inevitably subjective and affected by SHO satisfaction, the discipline of audit appeared effective in identifying and correcting deficiencies in an SHO training programme.

Keywords: audit, training, geriatric medicine, senior house officers

Work in the US has looked at the training offered to junior doctors studying geriatric medicine, ${ }^{1,2}$ but in the UK interest has centred upon the adequacy of training offered to senior registrars, training for consultant posts in the specialty. ${ }^{3,4}$ In contrast with senior registrars, senior house officers (SHOs) come to the subject from a variety of backgrounds, and have a wide variety of career intentions. ${ }^{5}$ It is therefore difficult to ensure provision of effective training, appropriate to the needs of all SHOs; especially as posts differ considerably in their content of acute and rehabilitative experience.
Our department is divided between three hospitals and employs 30 SHOs each year. Although this has the advantage that many local general practitioners and hospital clinicians will have received training within the department, it means that each year we need to attract a sizeable proportion of local graduates. The quality of training that we offer will clearly influence future recruitment. Although the Post-Graduate Dean acts as a commissioner in his funding of these SHO posts, audit programmes usually concentrate on the concerns of purchasers of clinical services, and have rarely looked at the quality of training.

We set out to structure our training programme, using audit to ensure that the training offered was appropriate to the needs of our SHOs.

\section{Methods}

The British Geriatrics Society's training committee has reviewed the subject of training for all grades of trainees in geriatric medicine, ${ }^{6}$ and made recommendations that constitute a summary of the training that should be offered. Six 'General professional' and 10 'Geriatric medicine' SHO training objectives were identified (box 1), and we used these as the framework for our audit. For each objective our audit standard simply required that all SHOs be satisfied that they had received adequate training.

At the end of their six-month appointment, each of our 15 SHOs received a short, anonymous postal questionnaire asking about formal and informal training. Each of the 16 objectives was presented, and SHOs were simply asked to grade the training they had received as either 'adequate' or 'inadequate'. A follow-up reminder letter achieved a final response rate of $87 \%$.

For three of the training objectives, less than $35 \%$ of SHOs felt that adequate training was being provided (figure 1). Training in performance of practical procedures (objective 2), in the assessment of multiple problems in the disabled patient (objective 9), and in the assessment of patients requiring institutional care (objective 14) were all felt to be covered inadequately.

In order to demonstrate the effectiveness of audit in improving the training offered to SHOs, we subsequently completed the cycle of audit (box 2), in the form of a controlled trial. Although data were collected from all three hospitals, the questionnaire results were 


\begin{tabular}{|c|c|c|}
\hline \multirow{2}{*}{$\begin{array}{l}\text { British Geriatrics Society training } \\
\text { objectives for SHOs in geriatric } \\
\text { medicine }\end{array}$} & \multicolumn{2}{|c|}{ Elements of the audit cycle } \\
\hline & 1 Define & improvement of SHO training in \\
\hline $\begin{array}{l}\text { General professional training: } \\
1 \text { Increase clinical skills of history taking, } \\
\text { mental and physical examination, diagnosis } \\
\text { and preparation of an initial management } \\
\text { plan } \\
2 \text { Increase skills in practical procedures such } \\
\text { as chest aspiration, paracentesis, } \\
\text { cardiopulmonary resuscitation, etc } \\
3 \text { Develop communication skills with the }\end{array}$ & $\begin{array}{ll}2 & \text { Agree } \\
& \text { standards: } \\
3 & \text { Perform audit: } \\
4 & \text { Identify } \\
& \text { problems: } \\
5 & \text { Modify } \\
& \text { practice: } \\
6 & \text { Repeat audit: }\end{array}$ & $\begin{array}{l}\text { British Geriatrics Society's } \\
\text { training objectives } \\
\text { postal questionnaire } \\
\text { target objectives where training } \\
\text { is inadequate } \\
\text { focus improved training on } \\
\text { target objective } \\
\text { repeat questionnaire }\end{array}$ \\
\hline
\end{tabular}

3 Develop communication skills with the general practitioner and other health care workers by developing interpersonal skills and written communication skills

4 Develop communication skills with patients and relatives, informing them about medical problems, breaking bad news and dealing with bereavement

5 Continue to develop professional attitudes, eg, confidentiality, personal conduct, ethical issues

6 Develop understanding of the role of continuing medical education in personal development by participating in teaching, case presentations, and clinical audit

Geriatric medicine:

7 Ability to assess the presenting complaints of elderly patients by awareness of importance of information from carers; by building a problem list and differential diagnosis

8 Ability to provide an initial functional and social assessment

9 Knowledge of the frequency of multiple pathology and the causes of nonspecific presentation in the elderly in the acute and less acute situation, in particular the interaction with disability

10 Knowledge of the efficacy and appropriateness of investigations in the ill elderly

11 Knowledge of the therapeutic and prescribing needs for the elderly

12 Knowledge of the purpose of rehabilitation. Ability to identify those who require rehabilitation, and identify the medical factors relevant to the rehabilitation process

13 Knowledge of community support services available for frail elderly, and relevance of discharge planning

14 Knowledge of criteria for institutional care of the elderly

15 Knowledge of medical needs of frail elderly who require continuing nursing care

16 Knowledge of ethical issues involved in medical care of the elderly

\section{Box 1}

Figure 1 Percentage of SHOs reporting adequate training for target and other $\square$ objectives: results of initial audit of all three hospitals
Box 2

only presented and discussed at the departmental audit meetings attended by the consultants and registrars of the 'intervention' hospital. SHOs are attached to individual consultants, and consultants from the two 'control' hospitals were not involved in this audit meeting. Though aware that the audit was being performed, these consultants were not informed of its initial findings, and were unable to respond by modification of the training offered to their own SHOs.

In the intervention hospital, teachers were was able to respond to the deficiencies identified by the initial audit, and these were targeted for particular attention in teaching over the following six months. There was no increase in formal teaching time, but informal training, such as that offered on ward rounds, was able to focus specifically on these target areas.

To assess the effect of this modification of training, the audit was repeated six months later, an identical questionnaire being sent again to SHOs in all three hospitals.

\section{Results}

In the intervention hospital, the adequacy of training over the 16 objectives increased from $59 \%$ at first audit to $73 \%$ at re-audit (figure 2), while there was no such increase in the control hospitals (a change from $60 \%$ to $57 \%$ ). While this improvement did not achieve statistical significance (table 1), a more impressive change was evident when the adequacy of training for the three target objectives was considered. Here there was an improvement from $38 \%$ to $69 \%$ which, when compared with a slight deterioration from $25 \%$ to $22 \%$ in the controls, proved statistically significant at $\mathrm{p}<0.05$ on a $\chi^{2}$-test (table 2).

\section{Discussion}

Individual training objectives vary in their relevance to SHOs with differing career intentions; half of our SHOs intended careers in general practice, while the rest were planning to continue in one or other hospital specialty. Similarly, different SHO posts offer differing clinical experience; some wards primarily accept emergency admissions, some only accept referrals for rehabilitation, and others combine the two roles. Such issues were considered by the British Geriatrics Society

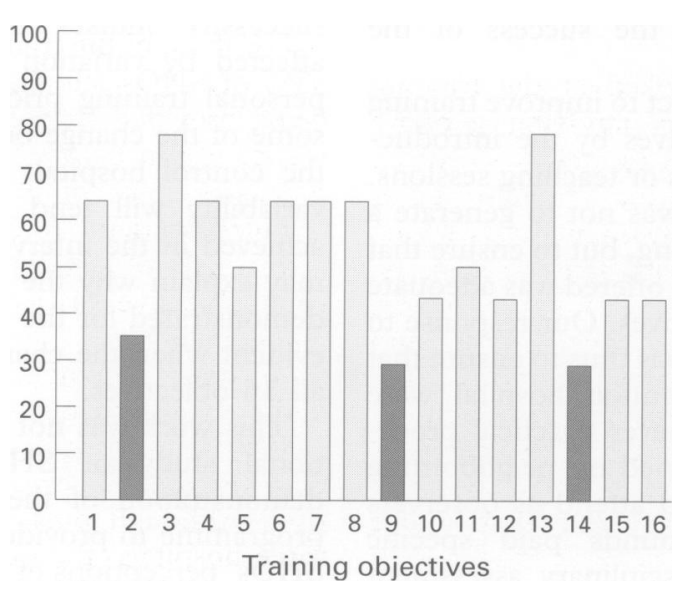


Figure 2 Percentage of SHOs reporting adequate training for target and other $\square$ objectives: change between initial audit and re-audit in intervention and control hospitals

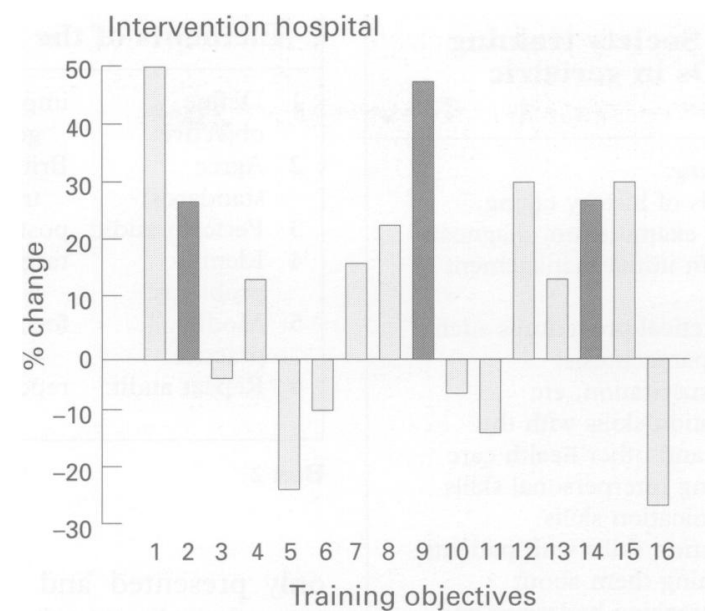

Table 1 Adequacy of training for all 16 objectives

\begin{tabular}{lll}
\hline & Audit (\%) & Re-audit (\%) \\
\hline Intervention hospital & 38 & 73 \\
Control hospitals & 25 & 57 \\
\hline
\end{tabular}

$\chi^{2}$ test: $p=$ not significant

Table 2 Adequacy of training for the three target objectives

\begin{tabular}{lll}
\hline & Audit (\%) & Re-audit (\%) \\
\hline Intervention hospital & 38 & 69 \\
Control hospitals & 25 & 22
\end{tabular}

$\chi^{2}$ test: $\mathrm{p}<0.05$

when originally defining the training objectives, which makes these objectives particularly appropriate for use in audit of SHO training. The recommendations were generally welcomed by SHOs, and accepted as a summary of the areas in which we have a responsibility to provide training.

The use of questionnaires is inevitably subjective and may be affected by SHO satisfaction. It is therefore possible that part of the demonstrated improvement was a consequence of improved satisfaction with a training programme perceived as responsive to their needs. Since greater SHO satisfaction is in itself a desirable outcome, this possibility does not detract from the success of the approach.

Clearly one might expect to improve training for specific target objectives by the introduction of additional lectures or teaching sessions. However, our intention was not to generate a new programme of teaching, but to ensure that the training already being offered was adequate in respect of all 16 objectives. Our response to the initial audit findings was thus to ensure that all SHOs in the intervention hospital were routinely informed whenever practical procedures were to be performed on neighbouring wards, so that they could attend as observers (objective 2). Ward rounds paid specific attention to the multidisciplinary assessment

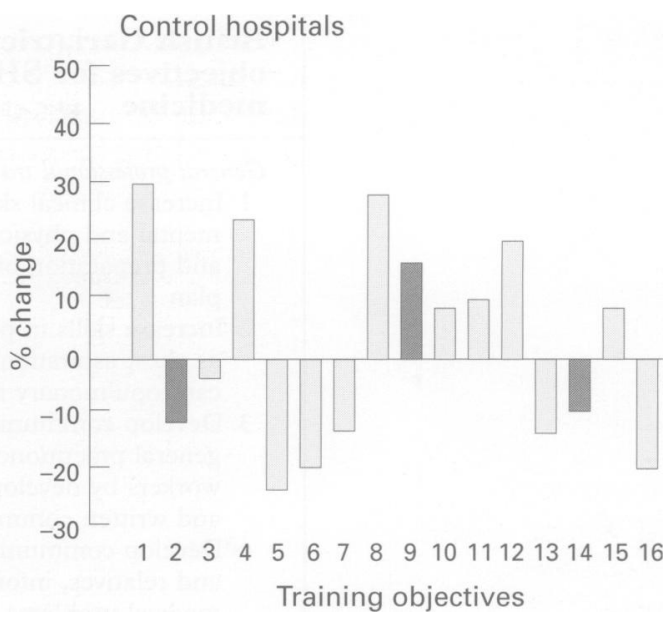

Summary/ learning points
- formal training objectives are increasingly well
defined for individual clinical specialties
- such objectives are ideally suited for use as a
standard in audit of postgraduate training
- the discipline of audit appears effective in
identifying and correcting deficiencies in
training

Box 3

of frail or disabled patients presenting with a nonspecific problem, such as confusion, drowsiness or immobility (objective 9 ). Ward multidisciplinary meetings paid especial attention to explaining and discussing the reasons underlying decisions on the institutional care placement of patients (objective 14).

Clearly there is considerable overlap between different objectives, and the marked improvement in objective 1 noted in the intervention hospital at re-audit (figure 2) may be a consequence of its similarity to one of the target objectives (objective 9).

As each SHO only spends six months with us it is not practical to complete an audit cycle within a single intake of SHOs, and such an approach would be inappropriate as training would inevitably be less complete at the initial audit than at re-audit. Thus, our approach was retrospective; questioning the training already received. As a result, a continuing process of audit will address successive intakes of SHOs and may be affected by variation such as that in SHOs' personal training priorities. This will explain some of the change between the two audits in the control hospitals (figure 2). Clearly, this variability will tend to obscure the change achieved in the intervention hospital, and this may explain why the significant improvement demonstrated for the target objectives was not evident when the change was considered over all 16 objectives.

This work was not intended as an observational study of SHO training, but as a demonstration of the use of a simple audit programme to provide structured feedback on SHOs' perceptions of their training. The list of 
training recommendations provided an excellent framework for the audit standard, and the discipline of audit appeared effective in identifying and correcting deficiencies in training. As

1 Counsell S R, Katz P R, Karuza J, Sullivan GM. Resident training in nursing home care: survey of successful educational strategies. F Am Geriatr Soc 1994; 42: 1193-9.

2 Reubens DB. Fellowship training in geriatrics. $\mathrm{Am} \mathrm{f} \mathrm{Med}$ 1994; 97: 18S-20S.

3 Sandler $M$. Senior registrar training in geriatric medicine 1977-1990. f R Coll Physicians Lond 1991; 25: 304-5.

4 Sandler M. Training experience and views of recently appointed consultants in geriatric medicine. $f R$ Coll Physicians Lond 1992; 26: 44-6. similar objectives are available for other grades and specialties, the approach deserves wider consideration.

5 Committee of Postgraduate Medical Deans (COPMED) and the UK Conference of Postgraduate Deans. SHO training: tackling the issues, raising the standards. London: Royal College of Physicians, 1995

6 British Geriatrics Society. Guidelines, policy statements and statements of good practice. London: Royal College of Physicians, 1994.

Hector Berlioz (1803-1869) was born in la Côte-Saint-Andre near Grenoble, son of a successful country doctor. Hector studied medicine in Paris, torn between it and opera and concert-going. Music won because the University was closed for a critical few months during $1822-3$ when he was in his final year as a medical student and he moved to music studies at the Conservatoire. He enjoyed international fame during his lifetime as a great French romantic composer. He died in January 1869. - DG Fames 